\title{
Supplemental oxygen and quality of sleep in patients with chronic obstructive lung disease
}

\author{
JAMES L MCKEON, KEITH MURREE-ALLEN, NICHOLAS A SAUNDERS
}

From the Department of Thoracic Medicine, Royal Newcastle Hospital, and the Discipline of Medicine, University of Newcastle, Newcastle, New South Wales, Australia

ABSTRACT The hypothesis that supplemental oxygen could improve the quality of sleep was tested in: 23 consecutive patients (14 male, nine female; age 42-74 years) with chronic obstructive lung disease $e_{\omega}^{+}$ (mean (SD) $\mathrm{FEV}_{1} 0.81(0.32)$ litre, $\mathrm{FEV}_{1} / \mathrm{FVC} 37 \%$ (12\%). Patients breathed compressed air or $\vec{\infty}_{\infty}$ supplemental oxygen via nasal cannulas on consecutive nights in a randomised, double blind, $\stackrel{+}{\circ}$ crossover trial. Quality of sleep was assessed by questionnaire and by electroencephalographic sleep? staging. The study had a power of $80 \%$ to detect, at the 0.05 level, a $20 \%$ improvement in total sleep $\vec{z}$ time. Seventeen patients slept for two nights in the laboratory. Oxygenation during sleep was improved by oxygen administration, but there was no improvement in quality of sleep. There was an今 acclimatisation effect with better sleep on the second night. Six patients spent an additional $\vec{\varphi}_{\vec{\rho}}$ acclimatisation night in the laboratory as well as the two study nights. There was no difference in sleep ${ }_{0}^{\infty}$ quality between the second and third nights or between the compressed air and the oxygen nights in these patients. Subgroups of patients with an arterial carbon dioxide tension of over $43 \mathrm{~mm} \mathrm{Hg}$ $(5.7 \mathrm{kPa})(\mathrm{n}=12)$ and arterial oxygen saturation of less than $90 \%(n=11)$ while awake did not show any improvement in quality of sleep on the oxygen night. It is concluded that supplementalo oxygen improves nocturnal oxygenation but does not immediately improve the quality of sleep in the laboratory in patients with chronic obstructive lung disease.

\section{Introduction}

Patients with chronic obstructive lung disease experience falls in arterial oxygen saturation $\left(\mathrm{SaO}_{2}\right)$ during sleep ${ }^{1-5}$ and have poorer quality sleep than healthy, control subjects of a similar age. ${ }^{1}$ Whether supplemental oxygen improves the quality of their sleep, however, is uncertain. Three studies suggested an improvement, ${ }^{6-8}$ but the number of patients studied was small; a larger study did not show improved sleep quality. ${ }^{9}$ We therefore studied 24 patients with chronic obstructive lung disease who received compressed air or supplemental oxygen on consecutive nights in a randomised, double blind, crossover trial. We planned to compare quality of sleep between the compressed air and the oxygen night and also between the first and the second night.

\section{Methods}

The subjects were outpatients with chronic obstructive

Address for reprint requests: Professor N A Saunders, David Maddison Clinical Sciences Building, Royal Newcastle Hospital, Newcastle, New South Wales 2300, Australia,

Accepted 13 December 1988 lung disease $\left(\mathrm{FEV}_{1}<70 \%\right.$ predicted, $\mathrm{FEV} / \mathrm{FVC}$ $<60 \%$, with no significant change in spirometric measurements after a nebulised bronchodilator). No patient had asthma, left ventricular failure, or symp-o toms suggesting obstructive sleep apnoea. All patients $x$ gave informed consent for the study.

\section{CLINIC VISIT}

Patients were seen in the clinic, where a history was taken and physical examination and routine pulmon- ary function testing were carried out. The patients rested in the sitting position and arterial blood was drawn from the radial artery for analysis of $\mathrm{pH}_{\circ}^{N}$ oxygen tension $\left(\mathrm{PO}_{2}\right)$ and carbon dioxide tension $\left(\mathrm{PCO}_{2}\right)$ (Radiometer ABL-2). $\mathrm{SaO}_{2}$ was measured with an ear oximeter (Biox IIA, Ohmeda, Colorado) and ${ }^{\omega}$ haemoglobin concentration from a venous blood sample.

\section{SLEEP STUDIES}

Eighteen patients were studied during sleep on two consecutive nights in the sleep laboratory. In one्D patient, the EEG recording was not adequate foP staging sleep, so results are presented for only 1 h patients. A further six patients were studied for three 
consecutive nights, consisting of an acclimatisation night and two study nights. Patients received compressed air or supplemental oxygen by nasal cannula in a double blind, randomised, crossover design. Neither the patient nor the person who staged the EEG recordings knew the order in which the gas mixtures had been inhaled. On the compressed air night the flow rate was $11 / \mathrm{min}$ throughout the night. On the oxygen night the flow rate was started at $0.5 \mathrm{l} / \mathrm{min}$ and increased by $0.5 \mathrm{l} / \mathrm{min}$ every 10 minutes until $\mathrm{SaO}_{2}$ was at least $90 \%$. It was further increased in $0.5 \mathrm{l} / \mathrm{min}$ steps during sleep if $\mathrm{SaO}_{2}$ fell below $90 \%$ for at least 10 minutes, the aim being to keep $\mathrm{SaO}_{2}$ above $90 \%$ throughout the night.

Sleep stage was monitored with cup electrodes in standard positions for electroencephalography, chin electromyography and electro-oculography.$^{10}$ Arterial oxygen saturation was continuously monitored by an ear oximeter (Biox IIA). Movements of chest and abdomen were measured by an inductance plethysmograph (Respitrace Corporation, Ardsley, New York). Airflow at the nose and mouth was measured by thermocouples attached to nasal prongs. All signals were recorded on a 12 channel ink pen recorder (Model 78 Grass Instruments, Quincy, Massachusetts). The oximeter signal was also processed and stored by a desk top computer (Hewlett Packard 47804A, Waltham, Massachusetts) for analysis of the percentage of time spent below $85 \%$ $\mathrm{SaO}_{2}\left(\mathrm{TST}_{<85}\right)$. $^{11}$

Sleep was staged by the method of Rechtschaffen and Kales ${ }^{10}$ on the basis of 30 second epochs. During analysis the $\mathrm{SaO}_{2}$ record was masked. Total sleep period (TSP) was the time from the first occurrence of stage 2 (sleep onset) to final awakening. Total sleep time (TST) was TSP minus stage awake (W). An arousal was defined as a change in the EEG to either alpha rhythm or a low voltage, mixed frequency pattern and included arousals to wakefulness (more than 15 seconds of any epoch) and briefer arousals (less than 15 seconds of any epoch). After sleep staging was completed, the lowest arterial saturation during sleep was determined directly from the record.

A 16 item questionnaire ${ }^{12}$ was administered to each patient after awakening to assess the quality of the previous night's sleep. Patients were asked to nominate which study night they preferred and to compare their sleep in the laboratory with their usual sleep at home.

\section{STATISTICAL METHODS}

Mean differences between nights were compared by paired $t$ tests and $95 \%$ confidence intervals for the differences were calculated. ${ }^{13}$ The power of the study was calculated by a standard formula. ${ }^{14}$ Wilcoxon's signed rank test for paired data was used to analyse the questionnaires. The two period crossover trial was analysed for treatment effects, period effects, and interactions. $^{15}$

\section{Results}

Twenty three patients (14 male, 9 female; age range 42-74 years) had sleep studies that were adequate for sleep staging. No patient had obstructive sleep apnoea. Three patients had clinical and radiological evidence of bronchiectasis; five had chronic bronchitis with normal carbon monoxide gas transfer and 15 had a reduced carbon monoxide gas transfer. Table 1 shows the mean age, haemoglobin concentration, arterial blood gas tensions, and pulmonary function of the group. Four patients were current cigarette smokers, 18 were ex-smokers, and one had never smoked. Nine patients had a $\mathrm{PaO}_{2}$ less than $56 \mathrm{~mm} \mathrm{Hg}$ $(7.5 \mathrm{kPa})$, of whom seven had a history of right heart failure. Four patients had a $\mathrm{PaO}_{2}$ in the range $56-60 \mathrm{~mm} \mathrm{Hg}(7.5-8.0 \mathrm{kPa})$, of whom two had had right heart failure. Twelve patients had hypercapnia $\left(\mathrm{PaCO}_{2}>43 \mathrm{~mm} \mathrm{Hg}\right)(5.7 \mathrm{kPa})$. Seven of the nine patients with a history of right heart failure had ECG evidence of right ventricular hypertrophy or a dilated right ventricle from echocardiography. Six patients had secondary polycythaemia.

\section{SLEEP STUDIES}

In the 17 patients who spent two nights in the sleep laboratory there were no significant differences between the compressed air and oxygen nights in the amount of time spent in any sleep stage (fig 1, upper

Table 1 Characteristics of the patients

\begin{tabular}{|c|c|c|c|}
\hline & Mean & $S D$ & Range \\
\hline \multirow{13}{*}{ 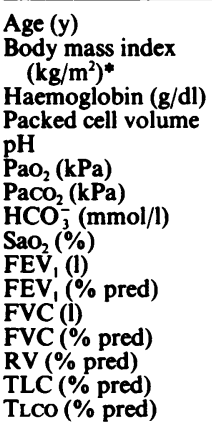 } & $63 \cdot 1$ & $9 \cdot 6$ & $42-74$ \\
\hline & $23 \cdot 0$ & 3.9 & $17-29$ \\
\hline & $15 \cdot 7$ & $2 \cdot 2$ & $11.4-19.4$ \\
\hline & $\begin{array}{l}0.47 \\
7.43\end{array}$ & 0.7 & $\begin{array}{l}0.35-0.61 \\
7.35-7.51\end{array}$ \\
\hline & $\begin{array}{l}7.43 \\
7.7\end{array}$ & $\begin{array}{l}0.04 \\
1.2\end{array}$ & $\begin{array}{l}7.35-7.56 \\
5 \cdot 5-10.9\end{array}$ \\
\hline & 5.9 & 1.2 & $4 \cdot 1-8 \cdot 3$ \\
\hline & $29 \cdot 2$ & 5.7 & $21 \cdot 8-39 \cdot 6$ \\
\hline & $\stackrel{89}{0.81}$ & $\begin{array}{l}4 \\
0.32\end{array}$ & $\begin{array}{l}80-96 \\
0.45-1.50\end{array}$ \\
\hline & & & 17.62 \\
\hline & $2 \cdot 26$ & 0.68 & $1.00-3.85$ \\
\hline & 67 & 17 & $35-121$ \\
\hline & 202 & 62 & $\begin{array}{r}100-334 \\
80-183\end{array}$ \\
\hline & 57 & 35 & 6-120 \\
\hline
\end{tabular}

${ }^{*}$ Body mass index $=$ weight $(\mathrm{kg}) /$ height $^{2}\left(\mathrm{~m}^{2}\right) .20-25=$ normal, 26$30=$ overweight, $>30=$ obese.

$\mathrm{PaO}_{2}$-arterial oxygen tension; $\mathrm{PaCO}_{2}$-arterial carbon dioxide tension; $\mathrm{HCO}_{3}^{-}$- bicarbonate; $\mathrm{SaO}_{2}$-arterial oxygen saturation; FEV , forced expiratory volume in one second; FVC-forced vital capacity; RV - residual volume; TLC - total lung capacity; TLCocarbon monoxide transfer factor. 
Fig 1 Sleep stage distributions for 17 patients who spent two nights in the laboratory, comparing the compressed air with the oxygen night and the first with the second night. Means and standard errors (bars) are shown. ${ }^{*} p<0.01$; ${ }^{* *} p<0.001$.

panel). Mean (SEM) sleep latency on the oxygen night was longer than on the compressed air night $(70(17) v$ 45 (7) min; $p<0.02 ; 95 \%$ confidence interval $(\mathrm{CI})$ for the difference between means 6-44 min). There was no significant difference between the nights in the number of arousals (fig 2) or in the number of sleep state changes. The mean lowest $\mathrm{SaO}_{2}(\%)$ during sleep on the oxygen night was higher than on the compressed air night (86 (3) $v 77(2) ; \mathrm{p}<0.01 ; 95 \%$ CI for difference between means 3-15\%). The mean \% time spent below $85 \% \mathrm{SaO}_{2}$ on the oxygen night was less than on the compressed air night (4 (2) v 41 (11); p < 0.01;

95\% CI for difference between means 13-55\%). Eleven patients did not require any increase in oxygen flow rate as $\mathrm{SaO}_{2}$ remained at or above $90 \%$ with the initial flow rate $(1 \mathrm{l} / \mathrm{min})$ before they went to sleep. In $\%$ the remaining six patients at least one increment in $\stackrel{\mathbb{Q}}{\stackrel{2}{2}}$ oxygen flow rate before sleep onset was needed. Mean $\overrightarrow{\vec{B}}$ sleep latency in these six patients did not differ 3 significantly from that found in the group receiving $1 \mathrm{l} / \mathrm{min}$ oxygen before sleep onset $(45$ (11) $v 83$ (14)? $\min$ ).

On the second night TST was longer than on the first night and there was more REM sleep (fig 1, table 2 ). There were no significant differences between the two nights in sleep latency, arousals, lowest $\mathrm{SaO}_{2}$ during sleep, or \% TST $<85$. There were no significant inter- $\delta$ actions between treatment and period effects (table 2).

Analysis of the questionnaire data showed no $\frac{\text { o }}{2}$

Table 2 Mean treatment responses and period effects for 17 patients who spent two nights in the laboratory

\begin{tabular}{|c|c|c|c|c|}
\hline & \multicolumn{2}{|l|}{ Treatment } & \multicolumn{2}{|l|}{ Period } \\
\hline & $\begin{array}{l}\text { Effect } \\
\left(\mathrm{O}_{2}-C A\right)\end{array}$ & $\begin{array}{l}\text { Significance } \\
(p)\end{array}$ & $\begin{array}{l}\text { Effect } \\
(N 1-N 2)\end{array}$ & $\begin{array}{l}\text { Significance } \\
(\boldsymbol{p})\end{array}$ \\
\hline $\begin{array}{l}\text { Sleep latency (min) } \\
\text { Total sleep period (TSP; min) } \\
\text { Total sleep time (\% TSP) } \\
\text { Stage awake (\% TSP) } \\
\text { Stage I (\% TSP) } \\
\text { Stage II } \% \text { TSP) } \\
\text { Stages III and IV (\% TSP) } \\
\text { Stage REM (\% TSP) } \\
\text { Arousals (per hour TSP) }\end{array}$ & $\begin{array}{r}25 \\
-15 \\
-5 \\
5 \\
3 \\
4 \\
0 \\
1 \\
0.1\end{array}$ & $\begin{array}{l}<0.02 \\
\text { NS } \\
\text { NS } \\
\text { NS } \\
\text { NS } \\
\text { NS } \\
\text { NS } \\
\text { NS } \\
\text { NS }\end{array}$ & $\begin{array}{l}10 \\
-23 \\
-18 \\
17 \\
-3 \\
-5 \\
-4 \\
-6 \\
-0 \cdot 4\end{array}$ & $\begin{array}{l}\text { NS } \\
\text { NS } \\
<0.01 \\
<0.01 \\
\text { NS } \\
\text { NS } \\
<0.05 \\
<0.01 \\
\text { NS }\end{array}$ \\
\hline \multicolumn{5}{|c|}{$\mathrm{O}_{2}-$ oxygen night; $\mathrm{CA}-$ compressed air night; N1-night $1 ;$ N2-night 2.} \\
\hline
\end{tabular}




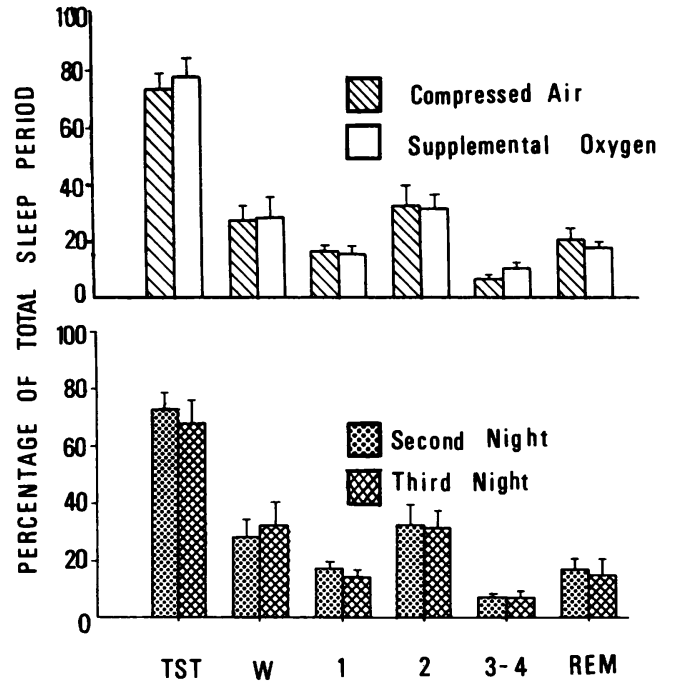

Fig 3 Sleep stage distributions for six patients who spent three nights in the laboratory, comparing the compressed air with the oxygen night and the second with the third night. Means and standard errors (bars) are shown. TST-total sleep time; $W$-awake; $R E M$-rapid eye movement sleep.

differences between the compressed air and oxygen nights for the 17 patients. When asked which night they preferred, nine patients chose the compressed air night and eight the oxygen night. There were, however, some significant differences between the first and second nights, favouring the second night: patients reported deeper sleep $(p=0.006)$ and fewer awakenings $(p=0.03)$, and thought that they slept better $(p=0.003)$ and that the second night was more like their usual sleep at home $(p=0.01)$. Two patients preferred the first night and 15 preferred the second night.

In the six patients who spent three nights in the laboratory there were no significant differences between the second and third nights in sleep stages (fig 3), sleep latency, arousals, lowest $\mathrm{SaO}_{2}$ during sleep, or $\% \mathrm{TST}_{<85}$. There were also no significant differences between the compressed air and oxygen nights in sleep stages (fig 3 ), number of sleep state changes, sleep latency, or arousals (fig 2). The mean lowest $\mathrm{SaO}_{2}(\%)$ on the oxygen night was higher than on the compressed air night (86 (4) v 75 (5); p < 0.001; $95 \% \mathrm{CI}$ for the difference $6-16 \%$ ). The mean $\%$ TST $_{<85}$ on the oxygen night was less than on the compressed air night (1 (1) v 45 (18); p < 0.05; 95\% CI for the difference $1-88 \%$ ).

Analysis of the questionnaire data for these six patients showed greater difficulty in going to sleep on the oxygen night $(p=0.01)$ but no other significant differences between the compressed air and oxygen nights. There were no significant differences between the second and third nights in the laboratory.
The group was stratified according to $\mathrm{PaCO}_{2}$ $(>43 \mathrm{~mm} \mathrm{Hg})(5.7 \mathrm{kPa})$ and $\mathrm{SaO}_{2}(<90 \%)$. There were no differences between the compressed air and oxygen nights in sleep stages or arousals for either subgroup.

\section{Discussion}

In 23 hypoxaemic patients with chronic obstructive lung disease supplemental oxygen did not improve the quality of sleep significantly when compared with placebo, as assessed by questionnaire or by sleep staging. There was an acclimatisation effect with improved quality of sleep on the second night. Even in the subgroup, however, who spent an additional acclimatisation night in the laboratory oxygen did not improve sleep quality significantly when compared with placebo.

An acclimatisation effect has been described in normal subjects undergoing EEG monitoring during sleep. ${ }^{16}$ In that study less wakefulness and stage 1 sleep and more REM sleep were found on the second night than on the first night. There were no further changes over the next two nights of the study. Acclimatisation to the laboratory may have reduced our chances of showing an improvement with oxygen. There was, however, no significant improvement in quality of sleep with supplemental oxygen in the subgroup who had an acclimatisation night. In the study of Fleetham et $a l^{9}$ the oxygen night was always preceded by a placebo night, maximising the chances of finding an improvement with oxygen. Despite this, these workers failed to find any improvement in quality of sleep on the oxygen night.

The quality of sleep of our patients was poorer than that reported previously for patients with chronic obstructive lung disease whose breathing was monitored during sleep; ${ }^{618}$ in particular, our patients had more wakefulness and less stage 2 sleep. Their quality of sleep was, however, similar to that of similarly aged patients with chronic obstructive lung disease previously reported from our laboratory. 'The present study had a power of $80 \%$ to detect, at the 0.05 level, a $20 \%$ increase in TST (\% TSP), a $25 \%$ increase in stage $2(\% \mathrm{TSP})$, and a $36 \%$ decrease in stage W $(\%$ TSP) with oxygen administration. These changes with oxygen would have resulted in near normal sleep architecture according to the findings of Carskadon and associates, ${ }^{17}$ who studied breathing and oxygenation during sleep in healthy elderly subjects. The longer sleep latency with oxygen is unexplained. On the oxygen night there was no difference in sleep latency between those patients who did and did not have adjustments made to flow rate before sleep onset. Thus, although the pattern of gas flow differed between the nights, increments in flow rate occurring on the oxygen night but not on the compressed air 
night, this seems unlikely to explain the difference in sleep latency that was observed.

Our negative findings contrast with the results of studies of patients with chronic obstructive lung disease in which sleep quality was felt to have been improved by supplemental oxygen. ${ }^{6-8}$ In the study of Kearley and associates the protocol was not optimal as only one night of sleep was studied; seven patients received room air followed by oxygen and only four patients received the gases in the reverse order. Goldstein and associates' studied patients on two consecutive nights with oxygen always on the first night. Total sleep time improved on the oxygen night but this difference did not achieve statistical significance. Calverley and associates ${ }^{6}$ studied six patients who had an acclimatisation night followed by two nights breathing compressed air or supplemental oxygen at $2 \mathrm{l} / \mathrm{min}$ from nasal cannulas in a randomised, double blind, crossover trial. On the oxygen night there was a significant reduction in stage $0+1 /$ TSP $(\%)(27 \%$ versus $15 \%)$ and an increase in stage REM/TSP (\%) (11\% versus $17 \%)$. The number of patients who received oxygen on the second study night was not reported.

The differences between the studies of Calverley et $a l^{6}$ and Fleetham et $a l^{9}$ were discussed in a recently published monograph on chronic obstructive lung disease. ${ }^{19}$ The authors ${ }^{19}$ suggested that hypercapnic patients were more likely to benefit from supplemental oxygen than eucapnic patients, noting that patients in the former study were hypercapnic (mean $\mathrm{PaCO}_{2}=$ $50 \mathrm{~mm} \mathrm{Hg}(6.7 \mathrm{kPa}))$ compared with those in the latter study (mean $\mathrm{PaCO}_{2} 44 \mathrm{~mm} \mathrm{Hg}(5.9 \mathrm{kPa})$ ). Our findings are against this interpretation because we found no significant improvement in quality of sleep with supplemental oxygen regardless of $\mathrm{PaCO}_{2}$. Moreover, the level of arterial oxygen saturation when patients are awake does not appear to influence the effect of oxygen on sleep quality as stratification of our patients according to whether or not $\mathrm{SaO}_{2}$ was below $90 \%$ did not show differences between the groups.

We thank Mr Steven Gyulay, Mrs Beverley Arnold, and Miss Dianne Murrell for technical assistance. We greatly appreciate the secretarial assistance of Mrs Joy Peate and Mrs Lyn Jeffrey. We thank Dr Dianne O'Connell for advice on statistics and Dr Les Olson and Associate Professor Michael Hensley for reviewing the manuscript. This study was supported by a grant from the National Health and Medical Research Council.

\section{References}

1 Cormick W, Olson LG, Hensley MJ, Saunders NA. Nocturnal hypoxaemia and quality of sleep in patients with chronic obstructive lung disease. Thorax 1986;41:846-54.

2 Douglas NJ, Calverley PMA, Leggett RJE, Brash HM.
Transient hypoxaemia during sleep in chronic. bronchitis and emphysema. Lancet 1979;i:1-4.

3 Flick MR, Block AJ. Continuous in-vivo monitoring of arterial oxygenation in chronic obstructive lunge disease. Ann Intern Med 1977;86:725-30.

4 Wynne JW, Block AJ, Hemenway J, et al. Disordered $\frac{\bar{\omega}}{\sqrt{5}}$ breathing and oxygen desaturation during sleep in patients with chronic obstructive lung disease (COLD) Am J Med 1979;66:573-9.

5 Leitch AG, Clancy LJ, Leggett RJE et al. Arterial blood $\overrightarrow{0}$ gas tensions, hydrogen ion, and electroencephalogram ${ }_{-}$ during sleep in patients with chronic ventilatory failure. Thorax 1976;31:730-5.

6 Calverley PMA, Brezinova V, Douglas NJ et al. The effect of oxygenation on sleep quality in chronics bronchitis and emphysema. Am Rev Respir Disi 1982;126:206-10.

7 Goldstein RS, Ramcharan V, Bowes G, McNicholas WT $\stackrel{\infty}{\oplus}$ Bradley D, Phillipson EA. Effect of supplementab nocturnal oxygen on gas exchange in patients with severe obstructive lung disease. $N$ Engl $J$ Med 1984;310:425-9.

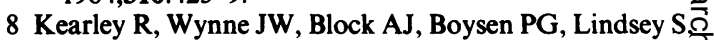
Martin C. The effect of low flow oxygen on sleep. disordered breathing and oxygen desaturation. A study of patients with chronic obstructive lung disease. Cheste 1980;78:682-5.

9 Fleetham J, West P, Mezon B, et al. Sleep arousals and oxygen desaturation in chronic obstructive pulmonary disease. The effect of oxygen therapy. Am Rev Respir Dis 1982;126:429-33.

10 Rechtschaffen A, Kales A, eds. A manual of standardised terminology, techniques and scoring systems for sleep stages of human subjects. Bethesda, Maryland 3 National Institutes of Health, 1968. (Publication 204.)

11 Slutsky AJ, Strohl KP. Quantification of oxygen satura tion during episodic hypoxaemia. Am Rev Respir Dis 1980;121:893-5.

12 Ellis $\mathbf{B}$, Johns $\mathbf{M}$, Lancaster $\mathbf{R}$, Ruptopoulos $\mathbf{P}$

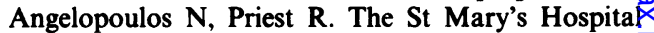
sleep questionnaire: a study of reliability. Sleeps 1981;4:93-7.

13 Gardner MJ, Altman D. Confidence intervals rather tham $P$ values: estimation rather than hypothesis testing. $B$ Med J 1986;292:746-50.

14 Colton R. Statistics in medicine. 1st ed. Boston: Little Brown and Company, 1974:142-6.

15 Hills M, Armitage P. The two-period cross over clinica) trial. Br J Pharmacol 1979;8:7-20.

16 Agnew HW, Webb WB, Williams RL. The first night effect: an EEG study of sleep. Psychophysiolog, 1966;2:263-6.

17 Carskadon MA, Brown ED, Dement WC. Sleep fragmentation in the elderly: relationship to daytime sleep tendency. Neurobiology of Aging 1982;3:321-7.

18 Brezinova V, Catterall JR, Douglas NJ, Calverley PMA Flenley DC. Night sleep of patients with chronic ventilatory failure and age-matched controls: numbe 5 and duration of EEG episodes of intervening wakeful ness and drowsiness. Sleep 1982;5:123-30.

19 George CF, Kryger MH. Sleep disorders in chroniø obstructive pulmonary disease. In: Hodgkin JE, Pettyo TL, eds. Chronic obstructive pulmonary disease. Curren concepts. Philadelphia: Saunders, 1987:197-214. 